\title{
Identity in First and Second Generation Migrants Belonging to a Tunisian Community in Mazara del Vallo (Sicily)
}

\author{
Anna Maria Ferraro ${ }^{1^{*}}$ \\ Cinzia Guarnaccia2,3 \\ Calogero lacolino ${ }^{1}$ \\ Francesca Giannone ${ }^{3}$ \\ ${ }^{1}$ Faculty of Human and Social Sciences, UKE - Kore University of Enna (Italy) \\ 2Department of Social Sciences and Humanities, University of Valle d'Aosta (Italy) \\ ${ }^{3}$ Department of Psychological, Pedagogical and Educational Sciences - University of Palermo(Italy) \\ *Corresponding Author Email address: annamariaferraro80@gmail.com
}

\section{Doi:10.5901/mjss.2015.v6n4s1p380}

\section{Abstract}

In Sicily, the increasing presence of immigrants has given the society an important challenge which has also required the adoption of an intercultural view and intervention designed to deepen the needs of migrants. Immigrants living in Sicily are distributed above all in coastal areas. The most numerous migrant communities come from Romania, Tunisia and Morocco. In the province of Trapani, the presence of foreigners reflects the regional distribution with migrants from Romania, Tunisia and Morocco. However, a different distribution of the population has been recorded in Mazara del Vallo, a small town in the province of Trapani, where a Tunisian community justifies the prevalence of Tunisians (77.7\%) above any other group of immigrants living in the city. The presence of the Tunisian community in Mazara Del Vallo for over forty years allows us to identify the variety in needs between first generation and second generation migrants. Particularly, this study explores the issue of redefining one's personal identity in both I and II generation migrants and the differences that emerge between them through the text analysis of interviews conducted on 40 immigrants, 20 pertaining to first generation migrants and the remaining 20 belonging to the second generation: parents and children, all members of the Tunisian community of Mazara del Vallo.

Keywords: identity, migration, generation, parents, adolescents

\section{Introduction}

The study of the reasons why immigrants require a residence permit is an investigation necessary to understand the migration phenomenon and to identify future trends. The presence of children, for instance, is a determining factor with respects to the migration project because it changes both the conditions of placement and the relationship with the place of origin. As long as migrants live alone, they can choose to be in a state "of social invisibility" remaining anchored to their traditions and limiting interaction with natives. However, the presence of children pushes them to participate in community life in order to reduce the conditions of segregation and to ensure that their children are given the best opportunity for social integration (Barbagli \& Schmoll, 2011; Ben Jellount, 2013; Favaro, 1990; Pace, 2004). Consequently, the migration project is deeply influenced by the presence of children who become the crux of dual projections by both natives and immigrant families. Indeed, for natives, the presence of migrants' children represents a clear sign in the tendency from temporary migration projects to permanent ones. For migrants, however, the presence of their children represents an uncertainty: the risk of a fracture regarding the past, certainties and traditional knowledge. This affects the perception of one's identity and its redefining process because the entire psychic inheritance dimension is strongly revisited within permanent migration projects ${ }^{1}$. In this way, dual tensions towards both the country of origin and that of residence are taken into consideration (Fabietti, 2012; Gozzoli \& Regalia, 2005; Remotti, 2010; Semprini, 2003). Therefore, considering the ambivalences of migrants about their own migration projects, in-depth analysis is needed in order to personalize interventions in line with their real needs (Ong, Fuller-Rowell \& Phinney, 2010). If, as stated by De Martino (1977), identity refers to the feeling to exist as a people with common sense in a context with sense, migration projects sedentary,

\footnotetext{
${ }^{1}$ Here, in particular, we refer to the groupanalytic theory on the development of self (Napolitani, 1987; Lo Verso, 1994; Giannone, Ferraro, Lo Verso, 2011) that theorizes the identity as a continuous "unconscious confrontation" between two psychic instances: Idem (ie the tendency to be "identical" to be holders of values, beliefs, behaviors, etc. of original frameworks ) and Autós (the tendency to differentiate itself from original contexts).
} 
permanently subtracting the first generation migrants coming to the community, expose them to the double risk of ontological "lost in the world" (crisis of presence) or "lose the world" (cultural apocalypse) (De Martino, 1977). We believe that this risk, even unconsciously experienced, interfere with the task of integration in the first generation migrants, reflecting, sometimes in a conflicting way, in relation with the second generation migrants. In Sicily, in particular, the great presence of immigrants has given the society an important challenge which has also required the adoption of an intercultural view and interventions designed to deepen the needs of migrants. At the end of 2013, foreign residents in Sicily were 139, 410 (XXIII Caritas Migrants Immigration Report, 2013). Being that the majority of the immigrants live on the island because of work or family, they need a stable plan for placement in the social fabric of the region. Foreigners living in Sicily are distributed above all in coastal cities, especially in Palermo, Messina and Catania. The $63.4 \%$ of them are aged between 20 and 49 years; women and young people are prevalent, and the phenomenon of second generations has increased in importance. The most numerous foreign communities come from Romania $\left(28.4 \%{ }^{2}\right)$, Tunisia $(11.9 \%)$ and Morocco (9\%). In the province of Trapani, the presence of migrants reflects the regional distribution with migrants above all from Romania (34.8\%), Tunisia (33.8\%) and Morocco (6.3\%). However, a different distribution of the population has been recorded in Mazara del Vallo ${ }^{3}$, a small town in the province of Trapani. In this town, in fact, a Tunisian community has been established for over forty year justifying the prevalence of Tunisians (77.7\%) above any other group of immigrants living in the city.

Mazara, situated in the province of Trapani in Sicily, has a population of about 51, 413 inhabitants. It overlooks the Mediterranean Sea and it is $200 \mathrm{~km}$ away from the Tunisian coast of North Africa. In Mazara, there are more than 3,000 immigrants (the majority from Maghreb) living with their family and working in fishing, artisanal or agricultural activities. Interaction between Mazara and Tunisian communities has always existed as demonstrated by the presence of Italian companies in the territory of Tunisia. Nonetheless, the phenomenon of migration in its current form began in the late sixties of the last century. At that time, the demographic pressure in Tunisia and the reduction of labor on Italian fishing boats combined to create favorable flows to both countries. The number of Tunisian workers living in Mazara grew so rapidly that they now account for more than 400 families. These immigrants decided to occupy the houses left by citizens of Mazara who4moved to other residential areas of the city. The Tunisian demographic density was concentrated in the central area of the city, the so-called Casbah, which includes the historical center. In the Casbah, they live according to Arab-Islamic traditions and the entire neighborhood is scenery of a strong lure of their original culture ${ }^{5}$. But, despite Mazara often being called an example of multiculturalism, it actually only hosts "two separate communities", where its members continue to nourish latent distrust and racism6: the isolation of the Casbah reveals, in fact, the persistence of distrust -indifference rather than a real integration between natives and foreigners. This lack of integration has forced the Tunisian community to become highly self-sufficient over the years thus generating a strong delay in the integration process. The failure of the school system in its mandate of integration is evidence of how scarce communication between the two communities really is. In Mazara, there is, in fact, a Tunisian primary school'where the Italian language is not taught and where Tunisians can choose to enroll their children rather than in an Italian one. Over the years, this possibility generated a mechanism of extraterritoriality as regards to the first education level which, indeed, represented one more sign of racism. Sure enough, although the Tunisian primary school was initially aimed to defend the right of not losing their own cultural, educational and linguistic features, it is also responsible for the difficulties that young Tunisians have to deal with when they continue their education in the Italian schools ${ }^{8}$ (Cusumano 1994; Hannachi, 1998). The poor understanding of the Italian language, in fact, means that young Tunisians consider their diversity as inferiority:

\footnotetext{
${ }^{2}$ Percentages refer to the entire foreign population in the area.

${ }^{3}$ From Now on: Mazara.

${ }^{4}$ Benefiting from the investments of the post-earthquake reconstruction.

5 In the Casbah, there is the Mosque which, despite being housed in a garage, is recognized as an important place of worship. There are also clubs frequented by men only (according to the use) and some local shops. Moreover, without a great relevance to the conservation of the Arab-Islamic model, there is a primary school where they teach Tunisian Arabic, French, Koran but not Italian. ${ }^{6}$ Only recently, an interest in the Tunisian community has started to grow, visible thanks to a number of community centers whose purpose is to facilitate the integration of young Tunisians in the community of Mazara (through school activities and animation, etc. ${ }^{7}$ The school has existed for about thirty years. It was intended to mitigate the risk of a "loss of the cultural matrix" in the small Tunisian community and also to mitigate the risk that II generation migration become an obstacle to the return to their country of origin, as repeatedly claimed by the Tunisian Consul at public meetings.

8 In fact, after attending the Tunisian school in Mazara del Vallo the boys completed further educational levels with serious language deficiencies, being left behind and, therefore, identified as a problem by both classmates and teachers. Therefore, while for boys and girls who have returned permanently to the Fatherland this type of training can be functional, for those who remained in Italy, it is configured as a multiplier of the discomfort.
} 
experiences that contribute to their attitude of closure and distrust and that sometimes can result in aggression (Miliotti, 2006; Santarone, 2006). In this sense, the importance of socialization through their parents' experience is essential in the development of one's self as a member of a closed ethnic group or even more as part of a community that works towards membership and multiculturalism ${ }^{9}$ (Ferraro \& Lo Verso, 2012; French, Coleman \& Di Lorenzo, 2013; Lannegrand-Willems L. \& Bosma, 2009; Lo Coco, Inguglia \& Pace, 2005; Lo Coco, Peace \&Zappulla, 2000). For all that has been said, Mazara del Vallo represents an interesting observation laboratory for its ability of mutual exchange and coexistence of different cultural, linguistic and religious prerogatives not only between native and non-native citizens, but also between I and II generation migrants within the Tunisian community. This study analyzes the main differences in identity that emerged from an interview conducted on n. 40 immigrants (no. 20 of the first and n. 20 of the second generation) who were all members of the Tunisian community of Mazara, both parents and children. The aim of this study is to identify the main theme in all the interviews conducted and explore the differences among the various scripts according to generation (I or II) and gender. We assume that there is a strong collective theme on the issue of identity for all the interviewed migrants $(\mathrm{H} 1)$ and a difference in lexicon (that is, specific language and a different form of expression) according to both variables: generation (I or II) and gender (female or male) $(\mathrm{H} 2)$.

\section{Methods}

\subsection{Participants}

The research involved n. 40 Tunisian immigrants ( 20 of the first generation and 20 of the second generation), all belonging to the Tunisian community of Mazara Del Vallo (Sicily). An interesting thing is that all interviewees are related by kinship (they are parents and children). In particular: the group of 1st generation migrants is composed of 6 males ( $M_{\text {age }}=52.16$ years, age range $40-64$ years) and 14 females ( $M_{\text {age }}=42.28$ years, age range $=30-58$ years); while the group of 2nd generation migrants consists of 10 males ( $M_{\text {age }}=14.2$ years, age range $=13-15$ years) and 10 females ( $\mathrm{M}_{\text {age }}=14.4$ years, age range $=12-16$ years $)$.

\subsection{Materials and Procedures}

The people who participated in the research were all from a homeless shelter in Mazara according to their availability based on convenience sampling criterion. The aim of the interview was described to each participant and then they were asked to sign a consent form. The interview was conducted in premises that guaranteed confidentiality. On average, the interviews lasted 40 minutes. After filling in a part related to personal information, the participants were asked to answer no. 9 open questions about their family (eg. "What differences do you find between the current family and the family of origin?"), their habits (eg. "How do you usually spend your day?") and future prospects (eg. "What do you wish if you look to the future?"). The interviews were recorded and verbatim transcribed.

Interviews data are securely stored at our university while the transcriptions were carefully analyzed. Analyzes have been conducted with the help of the analysis software IRAMUTEQ (Ratinaud, 2009-2012) which is a freeware software designed by Pierre Ratinaud and Laboratoire LERASS's equipe of the University of Toulouse-Le Mirail. It enables the statistical analysis on corpus of text and it uses the interface $R$ as a support (www.r-project.com). IRAMUTEQ uses the ALCESTE classification method described by Reinert $(1983,1986,1990,2001)$ and it is based on the research of similarities. This kind of research looks for the presence of co-occurring forms of the same graphic forms (words or lexemes) in the text and in portions of it (Kalampalikis, 2003; Kalampalikis\& Moscovici, 2005) ${ }^{10}$. The goal of this method is to organize speech noting the "lexical classes" according to their frequency and being defined as typical for that portion of the text. We performed basic statistical analysis on the corpus of texts and then submitted texts (organized according to the groups that had produced them) to a descending hierarchic classification with the aim of joining the occurrences in thematic classes. The calculation of the value Chi2 $\left(X^{2}\right)$ for each occurrence means the belonging (strong/weak) to the same class and, consequently, the level with which each graphic form contributes to differentiate one class from another. Finally, the Factorial Analysis of Correspondences (AFC) allowed us to find new variables -factorswhich represent the information obtained from the analysis of classes in a concise way.

${ }^{9} \mathrm{And}$, in this regard, the school is a fundamental place.

10 The originality of the method Alceste can be traced in its algorithm (CHD) of descending hierarchic classification applied to text segments. This algorithm, as well as all the testing procedures, are taken from software IRAMUTEQ (Ratinaud, 2009; Ratinaud\&Dejean, 2009). 


\section{Results}

The corpus that we analyzed is composed of 4 sub-corpus related to the transcripts of the interviews taken from the first generation immigrants (mothers and children) and second generation immigrants (daughters and sons). The corpus consists of 13,209 occurrences (Token - that is, single worlds) and 1,230 active forms (Types - that is, all words used). So, the average of occurrences for each form is 10.74. The number of hapax (word with occurrence=1, so, those one which appear once in the text) is $542(4,10 \%$ of active forms). The calculation of the index Type/Token Ratio (TTR=9,31) refers to a poor and repetitive corpus composed of a colloquial and non-specific lexicon. The wordcloud ( see Figure 1) represents occurrences with different sizes according to the frequency. In it, we can observe the frequent presence of the word "being" followed by other words recalling family roles (mother, father, son, parent), places (Mazara, Tunisi) and, besides, words related to traditions (Muslim, religion) and daily activities (to work). Coherently with the hypothesis $\mathrm{H} 1$, this type of occurrences suggest the presence of a strong central theme on the issue of being (and therefore on identity). To re-define itself, this central theme seems to recall (in order of size): family roles, places of origin and residence, references to traditions and daily activities. This analysis highlights the importance of the issue of existence of every participant in the research and its link to everything contributes to re-define its identity.

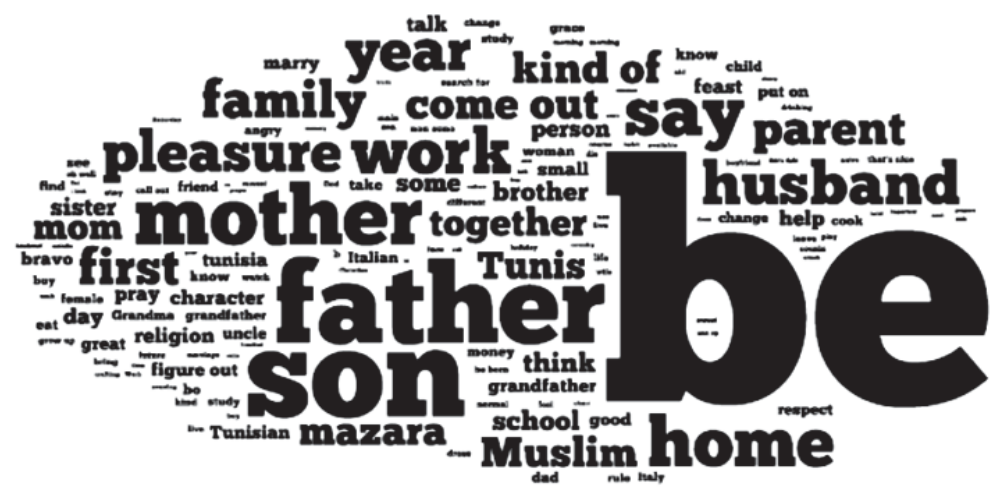

Figure 1 - Wordcloud

This dominant theme is deepened in the subsequent analysis which allows us to go into more detail by differentiating the way in which it is treated in the different lexical classes. The analysis of the thematic classes (see Table 1) found five distinct word classes. The lexical classes identify and differentiate significantly the parts of the speech according to their linguistic characterization ${ }^{11}$. In Table 1, the formation of 5 different word classes with the relative value of $x 2$ (significance index) can be observed. Significant differences in the structure of the text emerge according to the variables: F1 (1st generation women - mothers); M1 (1st generation men - fathers); F2 (2nd generation women - daughters); M2 (2nd generation men - children). It is also possible to observe the formation of the inexistence of any thematic class (identified by the abbreviation NSC Non-Specific Class), the values of which, however, do not appear significant. For this reason, it will not be taken into consideration in the comments below. Consistently with the hypothesis $\mathrm{H} 2$, the analysis of thematic classes identified different word classes which correspond to the discriminating variables that we chose (I or II generation and Female or Male gender). Deepening the content of the thematic classes that we identified, it can be noticed that it is related to the theme of identity in all classes, but in each class it is treated differently. In the thematic class F1 the most important ${ }^{12}$ words are: Tunisia (49.14), Grace (41.29), God (36.9), and besides: to marry (29.46), husband (25.41), son (13.13), to work (11.57), etc. These words suggest the presence of a strong link with origins, religion, and family. It also suggests that the main motivation for migration is family reunion. Just to follow, in fact, it is possible to observe the occurrence of terms such as: Italy (6.87), beautiful (6.87), teaching (5.65), retired (5.65), etc. interpreted as indicators of the presence of secondary motivations for migration. Finally, we observe an interesting occurrence of words (although not significant in terms of $\mathrm{X}$ ) of opening and hope such as: future (2.72), to talk (2.67), to see (2.1), women (2.1), etc. They

11 That is, the use of a specific language and partially different from the language in the text analyzed.

${ }^{12}$ The value in parentheses indicates the $x 2$ relative to each word, the terms listed are all statistically significant $p<.001$. 
are proof of the presence of a reflection on women's empowerment in Mazara (emancipated town of Italy). In the thematic class M1: words which are related with the themes of identity and the origin condition are prevalent. These are followed by other words similar to F1's ones which are sign of the central theme of family and family reunion. In this class, however, the fact that words like: son (18.21), wife (18.15), family (14.33), etc. are preceded and followed by words like: to think (33.64), to grow (22.53), poor (18.53), certain (12.19), money (11.07), etc. seem to indicate causes of migration, above all, economic reasons with the aim of escaping from a condition of poverty. Only in a second moment is this theme linked with the desire of family reunion and a better future for their children. In the thematic class F2: there is an occurrence of words from which an interrogation on the theme of their own identity shines through. There is also a double feeling of belonging (to the Tunisian community and to the Italian community) which involves doubts, contradictions and the theme of the loss of some thoughts and the conquest of others. Among the most frequent words we found were, in fact:to leave (33.83), to change (33.45), tradition (26.84), difference (26.84), to take (24.04), Tunisia (22:59), to know (22:59), switch (21.4), Arabic (21.4), to feel (16:49) , Italian (12.72), etc. So, while the content analysis of the first thematic classes (F1 and M1) emphasized the motivations of migration, in this class the speech on the reasons for migration project disappears and, rather, the theme of re-definition of their identity emerges strongly. One aspect of similarity with the class F1 may be noted, however, in the use of terms such as opening and hope: to talk (6.19), to change (6.19), to prepare (5.82). etc. These are probably part of a more global reflection on the female identity in Mazara del Vallo. In the thematic class M2: finally, it is possible to observe the occurrence of terms such as: exit (52.24), to be (11.63), angry (10.63) respect (10.5), Saturday (9.85), stealing (7:37), right (6:37), good (5:58), rule (4.43), and so on. These terms, also, seem to point to a reflection on identity, on what is allowed, on how best to behave (eg. anger, respect) and on the comparison between interior possibilities (eg. Out, Saturday) and prohibitions (right, rule, etc.). From this point of view, the topics that emerged from the content analysis of the thematic class M2 appear to be in continuity with those of the class F2, with the difference that, while in class F2 thematic reflection is discussed in more general terms, in the class M2 thematic words seem necessary to decline the subject identity in more concrete aspects of adolescent's daily life. Overall, and in line with the hypothesis $\mathrm{H} 2$, content analysis of linguistic occurrences for thematic classes allowed us to detect differences (even within the dominant theme "being / identity") among the different classes. Furthermore, just from this analysis, it can be outlined a greater thematic proximity according to (I or II) generation variable than to (M/F) gender variable. Indeed, while II generation migrants (both male and female) wonder about the theme of identity and its components (believes, behaviors, prohibitions etc.) which recall, indirectly, the tradition versus change issues, I generation migrants (both male and female) seem more anchored to their original cultural contexts and accustomed to commemorate the original conditions and the reasons for the trip ( where they found important elements of continuity as regards to their own identity).

Table 1 - Descending hierarchic analysis

\begin{tabular}{clcc}
\hline Thematic Class & Group & $\chi^{2}(\mathbf{p})$ \\
\hline F1 & Mothers & (Female $1^{\circ}$ generation) & $11.66(<.001)$ \\
M1 & Fathers & (Male $1^{\circ}$ generation) & $14.02(<.001)$ \\
F2 & Figlie & (Female $2^{\circ}$ generation) & $8.65(<.003)$ \\
M2 & Figli & (Male $2^{\circ}$ generation) & $28.95(<.001)$ \\
CNS & CNS & Non-specific class & --- \\
\hline
\end{tabular}

On these differences, clearer results come from the dendrogram analysis and from Factorial Analysis of Correspondences (AFC) related below. Dendrogram analysis (see Figure 2) and Factorial Analysis of Correspondences ( see Figure 3) allow us to verify a greater proximity among classes according to the generation variable. In the dendrogram, we observe, in fact, the group of the classes F1+M2 and F2+M2 which confirms the hypothesis $\mathrm{H} 3$, which is a deeper proximity among thematic classes because of their generation rather than because of their gender. This hypothesis is further confirmed by Factorial Analysis of Correspondences that allows us to see the arrangement of thematic classes on a factorial plane (see Figure 3) and the oppositions among the different groups from the analysis of correspondences among more frequent occurrences. In figure 3, we observe, in fact the classes M2 and F2 on the left of the axis and the classes M1 and F1 on the right. More specifically, we note the prevalence of two factors. The first factor explains that $32.45 \%$ of the variance while the second factor explains the $27.06 \%$. Since the sum of these two factors sums up to $59.51 \%$ of the variance, we limit the analysis to these two factors (see Table 2). 


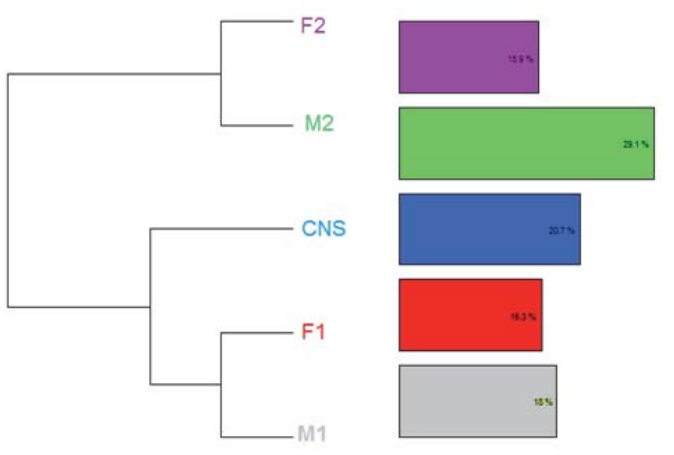

Figure 2 - Dendrogram of the hierarchic analysis on the whole corpus.

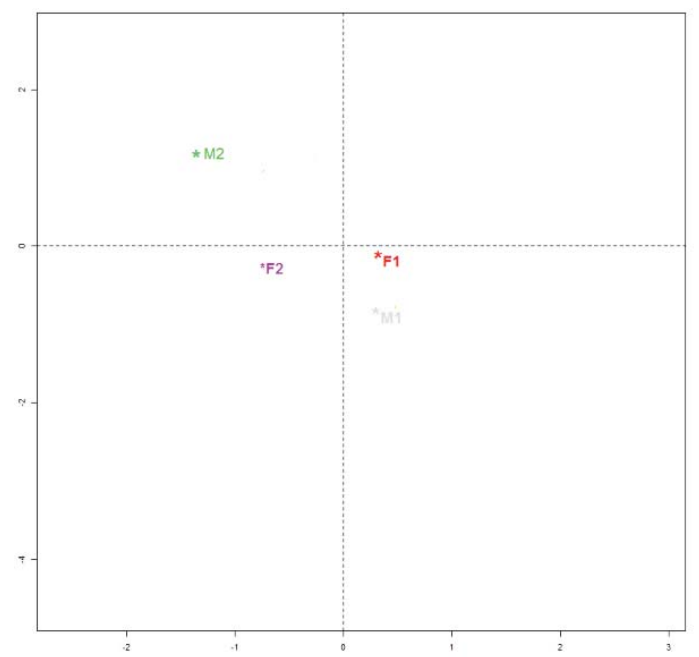

Figure 3 - Factorial Analysis of Correspondences (AFC)

Table 2 - Factorial Analysis of Correspondences (AFC): factors extracted and explained variance

\begin{tabular}{ccc}
\hline & Autovalues & $\%$ \\
\hline Factor 1 & 0,33 & 32,45 \\
Factor 2 & 0,27 & 27,06 \\
Factor & 0,22 & 22,02 \\
Factor 4 & 0,19 & 18,47 \\
\hline
\end{tabular}

\section{Discussion}

In the first part of the investigation, a substantial confirmation of our initial hypothesis can be noticed. We suppose, in fact, to observe an important central theme of identity in all texts that migrants produced during interviews and also to observe some differences according to variables we chose for this study (belonging to I or II generation and to male or female gender). Analyzes confirmed both the presence of a strong central theme of identity and the presence of different ways of dealing with this theme according to the variables that we selected. Furthermore, they allowed us to verify the greater involvement of the generation variable (rather than the gender variable) as regards to the theme of the redefinition of identity, as we hypothesized. Particularly in this regard, it had previously emerged through content analysis that the first 
generation (both $\mathrm{F}$ and $\mathrm{M}$ ) tends to highlight the motivation for their trip, therefore, resuming the theme of their origins and anchoring some important aspects of their identity to them. However, the second generation (both $\mathrm{F}$ and $\mathrm{M}$ ) does not search for ${ }^{13}$ any anchors that links their own identity to the memories of their place of origin. Moreover, the second generation appears committed to wonder about their origins, in an attempt to reconcile the dual sense of belonging that resurfaces in the interviews, bringing with it a disorienting mix of contradictions, conflicts and uncertainties. So, if migration can be read as a phenomenon of restructuring both personal and social identity, the generation gap seems to be the element that most discriminates the way they live this "restructuring". This is, in fact, the variable which seems to justify the difference among interview scripts: while in I generation migrants scripts, we can read more references pertaining to cultural contexts (such as, the Tunisian cultural matrix), in II generation scripts, the reference to this matrix becomes softer, doubts multiply, contradictions find a new space (unknown regarding first generation scripts) and, according to the clinical literature, the interrogation about their own identity becomes stronger and more problematic. Literature provides a variety of input in order to interpret this element: first of all, we can suppose that the work done on the redefinition of identity, that is, the dialectic Idem/Autòs (Ferraro \& Lo Verso, 2007; Ferraro \& Lo Verso, 2008) is more present in II generation migrants scripts because it is related to a period of adolescence when we tend to weaver away from our family's suggestions to integrate elements of other cultures in our way of being (Confalonieri \& Pace, 2008; Ferraro \& Lo Verso, 2011; Giannone, Ferraro \& Lo Verso, 2011; Ingoglia, Lo Coco, Pace, Zappulla, Liga \&Inguglia, 2004; Pace \& Zappulla, 2009; Skowron\& Platt, 2005). In the specific case of II generation migrants, however, the difficult process of recognition of oneself independently from their family matrix is complicated by the fact that family's modus vivendi and rules can be in open conflict with the host society's ${ }^{14}$ modus vivendi and rules. This arouses ambivalent feelings regarding the paths of growth and integration both in adolescents and in their parents. Adolescents, in fact, in order to live like their peers, may exacerbate the normal conflicts with parents, highlighting and using the differences between cultures as a support to the already difficult task of "differentiating" family matrices (by risking, however, to oversimplify matters relating to the past and origins, that is, to oversimplify the fundamental dimension of identity which is the idem). On the other hand, parents, who have already dealt with a different cultural context, can see the risk of a fracture with the past in their children and, consequently, nourish ambivalence towards their integration and can sometimes consider the distance from the native social fabric as an "opportunity" to ensure cultural and transgenerational transmission for their children that inevitably tends to change as a result of the migration process. Undoubtedly, our study presents numerous limitations due to the restricted sample and also to the noted "distrust" of the Tunisian community. An additional limit is given by the geographical sectorization in one territory and the focus on a single community that does not allow us to generalize the data to the set of migration. However, this exploratory study can be considered successful due to the use of in-depth "clinical" instruments (such as the semi-structured interviews) and the "in depth" analysis of narratives through the content analysis which has given us the opportunity to overcome the restrictions of some qualitative research identifying topics useful in understanding the phenomena. In conclusion, we observe the gaps of this and other studies of this type in terms of research but, above all, in terms of implications for clinical intervention. The further understanding of migration in itself and identity construction of new generations migrants, in fact, is the base on which new studies can be built recognizing the facets of this process by identifying critical points and areas of resource. The knowledge development (reliable for future studies) encloses the possibility of a better intervention for clinical and social support addressed to those communities that continuously face more massive migration flows.

\section{References}

Barbagli, M., Schmoll, C. (2011). La generazione dopo. Stranieri in Italia. Bologna: II Mulino.

Ben Jellount, T. (2013). II razzismo spiegato a mia figlia. I nuovi razzismi in Italia. Milano: Bompiani.

Confalonieri, E.; Pace, U. (2008). Sfaccettature identitarie. Come adolescenza e identità dialogano tra loro. Milano: Unicopli.

Cusumano, A. (1994). Immigrazione straniera, integrazione e scuola. II caso di Mazara del Vallo. Senza Frontiere 0, 23-38.

Caritas/Migrantes (2013). XXII Rapporto sull'immigrazione, Regione Sicilia.

De Martino, E. (1977). La fine del mondo. Contributo all'analisi delle apocalissi culturali. Torino: Einaudi.

Favaro, G. (1990). I colori dell'infanzia, bambini stranieri nei servizi educativi. Milano: Guerini Associati.

Giannone, F., Ferraro, A.M., Lo Verso, G. (2011). Gruppoanalisi Soggettuale e teoria del Self. In Lo Verso G., Di Blasi M. (Eds)

${ }^{13}$ Retracing the reasons for their own migratory journey or the one of their family.

${ }_{14}$ Especially if we think of the changes, in terms of identity references, made by the emergence of postmodernism in the West (Ferraro, 2011, Ferraro, Giannone\& Lo Verso, 2012, Ferraro, Guarnaccia, Mineo, Giusino, Ruggiero \&Giannone, 2014; Ferraro, Giannone\& Lo Verso, 2014) 
Gruppoanalisi Soggettuale (pp. 59-87). Milano: Raffaello Cortina Editore.

Gozzoli, C., Regalia, C. (2005). Migrazioni e famiglie. Percorsi, legami e interventi psicosociali. Bologna: II Mulino.

Hannachi, K. (1998). Gli immigrati tunisini a Mazara del Vallo. Trapani: Cresm.

Fabietti, U. (2012). Elementi di antropologia culturale. Milano: Mondadori.

Ferraro, A.M. Lo Verso, G. (2007). Disidentità e dintorni. Reti smagliate e destino della soggettualità oggi. Milano: Franco Angeli.

Ferraro, A.M., Lo Verso. G. (2008). Soggettualità: identità e disidentità. Psicotech 6(1), 37-43.

Ferraro, A.M. (2011). Disidentità: una sola moltitudine o solo molta solitudine?. Plexus 7, 11-23.

Ferraro, A.M., Lo Verso G. (2011). II transpersonale tra clinica e antropologia, la prospettiva gruppoanalitico-soggettuale. In Pergola, F.

(Ed) Alla ricerca delle informazioni perdute. L'inespresso transgenerazionale come vincolo alla crescita (pp. 77-85). Milano: Franco Angeli Milano.

Ferraro, A.M., Giannone, F., Lo Verso, G. (2012). Disidentità: una chiave di lettura per le nuove forme di psicopatologia?. Narrare i Gruppi. Etnografia delle interazioni quotidiane. Prospettive cliniche e sociali. 7 (1), 36-43.

Ferraro, A.M.; Lo Verso G. (2012). Contesti multipersonali e formazione dell'identità. In Ubaldeschi, D., (Ed). CSR COIRAG. Quaderno report 17, 17-36.

Ferraro, A.M., Guarnaccia, C., Mineo, C., Giusino, L., Ruggirello, A., Giannone, F. (2014). Dis-identity in the postmodern epoch: selfdifferentiation and interpersonal relationships before and after a group experience. Rivista di PsicologiaClinica, 1, 309-325.

Ferraro, A.M.; Giannone, F., Lo Verso, G. (2014) Dis-Identity: New Forms of Identity and Psychopathology - Socioanthropological Changes and Self-Development. World Futures, The Journal of New Paradigm Research. Vol. 70 (issue 7) 377-385.

French S.E., Coleman B.R., Di Lorenzo M.L. (2013). Linking Racial Identity, Ethnic Identity, and Racial-Ethnic Socialization: A Tale of Three Race-Ethnicities. Identity: An International Journal of Theory and Research, 13(1), 1-45.

Giannone, F., Ferraro, A.M., Lo Verso, G. (2011) "Gruppoanalisi Soggettuale e teoria del Self". In Lo Verso G., Di Blasi M., Gruppoanalisi Soggettuale. Milano, Raffaello Cortina Editore. pp. 59-87.

Ingoglia, S., Lo Coco, A., Pace, U., Zappulla, C., Liga, F., Inguglia, C. (2004). Percezione della relazione con i genitori: differenze individuali nella connessione e nell'autonomia in adolescenza. Psicologia clinica dello sviluppo 8(2) 307-320.

Lannegrand-Willems L., Bosma, A.H. (2009). Identity Development-in-Context: The School as an Important Context for Identity Development. Identity: An International Journal of Theory and Research, 6 (1), 85-113.

Lo Coco, A., Pace, U., Zappulla, C. (2000). I precursori dell'identità etnica in età infantile. Età Evolutiva. n. 66, pp. 77-85.

Lo Coco A, Inguglia C, Pace U. (2005). Children's understanding of ethnic-cultural groups. In: M. Barrett, E. Buchanan-Barrow. Children's understanding of society, 223-250, London: Hove: Psychology Press

Miliotti, A.G., (2006). E Nikolaj va a scuola. Milano: Franco Angeli.

Ong A.D., Fuller-Rowell, T.E., Phinney, J.S. (2010). Measurement of Ethnic Identity: Recurrent and Emergent Issues. Identity: An International Journal of Theory and Research, 10(1), 39-49.

Pace U., Zappulla C (2009). Identity Processes and Quality of Emotional Autonomy: The Contribution of Two Developmental Tasks on Middle-Adolescents Subjective Well-Being. Identity: An International Journal of Theory and Research, 9, 323-340.

Pace, E. (2004). L'Islam in Europa: modelli di integrazione. Roma: Carocci.

Remotti, F. (2010). L'ossessione identitaria. Roma-Bari: Laterza.

Santarone, D. (2006) (Ed). Educare diversamente. Roma: Armando Editore.

Skowron EA, Platt LF. (2005) Differentiation of self and child abuse potential in young adulthood. The Family Journal, 13, 281-290.

Semprini, A. (2003). La società di flusso. Senso e identità nelle società contemporanee. Milano: Franco Angeli. 